\title{
LA FRAGILIDAD DE LOS DERECHOS ${ }^{1}$
}

José CALVO GONZÁLEZ

Universidad de Málaga, España

\section{La vieja seguridad. Anteayer, a más de un siglo}

En el reloj de la memoria europea de Stefan Zweig (Viena, 1881- Petrópolis. Brasil, 1942), suenan al inicio de El mundo de ayer las horas volcadas al nostálgico recuerdo del viejo mundo de la seguridad.

"Si busco una fórmula práctica para definir la época de antes de la Primera Guerra Mundial, la época en que crecí y me crié, confío en haber encontrado la más concisa al decir que fue la edad de oro de la seguridad. Todo en nuestra monarquía austriaca casi milenaria parecía asentarse sobre el fundamento de la duración, y el propio Estado parecía la garantía suprema de esta estabilidad. Los derechos que otorgaba a sus ciudadanos estaban garantizados por el Parlamento, representación del pueblo libremente elegida, y todos los deberes estaban exactamente delimitados. Nuestra moneda, la corona austriaca, circulaba en relucientes piezas de oro y garantizaba así su invariabilidad. Todo el mundo sabía cuánto tenía o cuánto le correspondía, qué le estaba permitido y qué prohibido. Todo tenía su norma, su medida y su peso determinados (...) En aquel basto impero todo ocupaba su lugar, firme e inmutable, y en el más alto de todos estaba el anciano emperador; y si éste moría, se sabía (o se creía saber) que vendría otro y que nada cambiaría en el bien calculado orden. Nadie creía en las guerras, las revoluciones ni las subversiones. Todo lo radical y violento parecía imposible en aquella era la de razón.

Dicho sentimiento de seguridad era la posesión más deseable de millones de personas, el ideal común de vida. (...) Primero, sólo los terratenientes disfrutaban de tal privilegio, pero poco a poco se fueron esforzando por obtenerlo también las grandes masas (...) También hubo avances en el ámbito social; año tras año, el individuo fue obteniendo nuevos derechos, la justicia procedía

${ }^{1}$ Texto del Seminario impartido el 3 de marzo de 2005 en el Programa de Doctorado en Derechos Fundamentales. Asignatura de Teoría jurídica de los Derechos Fundamentales. Instituto de Derechos Humanos 'Bartolomé de Las Casas'. Universidad Carlos III de Madrid. 
con más moderación y humanidad e incluso el problema de los problemas, la pobreza de las grandes masas, dejó de parecer insuperable. Se otorgó el derecho de voto a grandes círculos cada vez más amplios y, con él, la posibilidad de defender legalmente sus intereses; sociólogos y catedráticos rivalizaban en el afán de hacer más sana e incluso más feliz la vida del proletariado... ¿ Es de extrañar, pues, que aquel siglo se deleitara con sus propias conquistas y considerara cada década terminada como un mero peldaño hacia otra mejor? Se creía tan poco en recaídas en la barbarie -por ejemplo, guerras entre los pueblos de Europacomo en brujas y fantasmas; nuestros padres estaban plenamente imbuidos de la confianza en la fuerza infaliblemente aglutinadora de la tolerancia y la conciliación. Creían honradamente que las fronteras de las divergencias entre naciones y confesiones se fusionarían poco a poco en un humanismo común y que así la humanidad lograría la paz y la seguridad, esos bienes supremos. Para los hombres de hoy, que hace tiempo excluimos del vocabulario la palabra "seguridad" como un fantasma, nos resulta fácil reírnos de la ilusión optimista de aquella generación, cegada por el idealismo, para la cual el progreso técnico debía ir seguido necesariamente de un progreso moral igual de veloz. Nosotros, que en el nuevo siglo hemos aprendido a no sorprendernos de cualquier nuevo brote de bestialidad colectiva, nosotros, que todos los días esperábamos una atrocidad peor que la del día anterior, (...) hemos tenido que acostumbrarnos poco a poco a vivir sin el suelo bajo nuestros pies, sin derechos, sin libertad, sin seguridad. Para salvaguardar nuestra propia existencia, renegamos ya hace tiempo de la religión de nuestros padres, de su fe en el progreso rápido y duradero de la humanidad; a quienes aprendimos con horror nos parece banal aquel optimismo precipitado a la vista de una catástrofe que, de un solo golpe, nos ha hecho retroceder mil años de esfuerzos humanos (...). Hoy, cuando ya hace tiempo que la gran tempestad lo aniquiló, sabemos a ciencia cierta que aquel mundo de seguridad fue un castillo de naipes"2.

\footnotetext{
2 ZWEIG, Stefan, El mundo de ayer. Memorias de un europeo, trad. de J. Fontcuberta y A. Orzeszek, El Acantilado, Barcelona, 2001, págs. 17-22. El lector podrá hallar una útil guía histórica donde seguir los acontecimientos de la política europea y mundial a lo largo de la era Bismark (1862-1890) y aproximarse al equilibrio de poder durante el período comprendido entre 1898 y 1914 consultando las obras de HEIGEL, Karl Theodor y ENDRES, Firtz, Tendencias políticas en Europa durante el siglo XIX, trad. de M. Sánchez Sarto, Edit Labor, Barcelona, 1930 (c.), y BRUUN, Geoffrey, La Europa del siglo XIX. 1815-1914 (1959), trad. de F. González Aramburu, FCE, México, 1974 ( $2^{\mathrm{a}}$ reimp.), págs. 194-238. Es también lectura provechosa SCHORSKE, Carl E., Viena fin-de-siècle: política y cultura, trad. de I. Menéndez, Edit. Gustavo Gili, Barcelona, 1981, para la situación austriaca entre 1867 y 1918. En España, como señala MAINER, José-Carlos, La Edad de Plata (1902-1931). Ensayo de interpretación de un proceso cultural, Los Libros de la Frontera, Barcelona, 1975, pág. 85, la novela de CIGES APARICIO, Manuel (1873-1936) Circe y el poeta (eds.: Edit. Mundo Latino, Madrid, 1926; Novelas de Manuel Ciges Aparicio, ed., introd. y notas de Cecilio Alonso, Conselleria de Cultura, Educació i Ciencia de la Generalitat Valenciana, València, 1986, 3 t. [Col. Clàssics valencians 3-4-5], y Edit. Siete Mares, Madrid, 2003), retrata en claves muy sencillas de ese mundo que conoció su edad dorada antes de la conflagración europea, visto desde la mirada de un poeta revolucionario en el París de 1914.
} 
El texto, que contiene casi todas sus paráfrasis posibles, precisa de muy pocos comentarios. No es difícil descubrir en él un gráfico y penetrante ejemplo de sobre qué dos condiciones básicas se suscitaba y sostenía en el cuadro de una mentalidad burguesa la relación armónica entre libertad y seguridad. Una era la independencia económica, facilitada bien por disponer de bienes patrimoniales (propiedad) o de abundancia de recursos financieros (capital), bien de coberturas o prestaciones sociales para disminuir o paliar el riesgo, lo cual se obtenía, respectivamente, mediante una libertad negocial sólo intermediada por requerimientos legales mínimos, y a través del desarrollo de un sistema seguros (de accidentes, de enfermedad, planes de jubilaciones, etc., como el ideado por el Canciller Bismack y que con rapidez se extendió a toda Europa). La otra fue psicológica y vino dada por la satisfacción de comprobar que las aspiraciones a la conservación del orden social se cumplían más perfectamente cuando, como en la naturaleza, se actuaba con la seguridad de los instintos; lo natural en sociedad consistía, pues, en evitar transiciones y cambios que pudieran perturbar la estabilidad, que ocasionaran inseguridad, razón por la cual el orden existente del mundo debía mantenerse en estado de tranquilidad para que así, efectivamente, perdurara. En consecuencia, la inseguridad artificial podía preverse y dejar de serlo, y en cuanto a la natural el mundo de la libertad más segura sería aquel que más valora la seguridad, de donde la libertad dependía de la seguridad. Y sin embargo, todo ese mundo de seguridad se derrumbó igual que si se tratara de "un castillo de naipes".

Al cataclismo de la Gran Guerra de 1914, sumaron nuevos efectos las revisiones y correcciones (Estado asistencial como especie de reeditado "contrato social" en una pujante sociedad industrial) que en la Europa de entreguerras (19181933) experimentó el Estado de Derecho liberal ${ }^{3}$, y al definitivo fracaso de éste -como igualmente de aquéllas- en el contexto de crisis de la República de Wei-

${ }^{3}$ LASKI, Harold J., El liberalismo europeo (1936), trad. de V. Miguélez (1939), FCE, México, 1953 (1 ${ }^{\text {a }}$ ed., $4^{\mathrm{a}}$ reimp.), sin restar la merecida importancia a los profundos progresos que al liberalismo se deben, ha señalado también con claridad las causas del fracaso de la doctrina liberal como implícitas e inasequibles a todo intento de refundación: "El individuo a quien el liberalismo ha tratado de proteger es aquel que, dentro de su cuadro social, es siempre libre para comprar su libertad; pero siempre ha sido una minoría de la humanidad el número de los que tienen recursos para hacer esta compra. Puede decirse, en suma, que la idea de liberalismo está históricamente trabada, y esto de modo ineludible, con la posición de propiedad. Los fines a los que sirve son siempre los fines de los hombres que se encuentran en esa posición" (págs. 16-17), concluyendo que "sin duda la idea liberal, como tal, trató de superar el medio en que fue engendrada. Sin duda, también, la urgencia con que fue predicada como idea ayudó a mitigar las consecuencias cabales de la sociedad a cuya formación contribuyó. Pero tan pronto como el liberalismo, como espíritu que informa las costumbres de las instituciones, trató de efectuar su transformación fundamental, se halló con que era prisionero del fin a cuyo servicio había sido destinado. Porque los hombres que lo sirvieron no creían en sus derechos como distintos a los de ese fin" (pág. 223).

${ }^{4}$ Vid. GAY, Peter, La cultura de Weimar (1968), trad. de N. Catelli, Argos Vergara, Barcelona, 1984, y ESTÉVEZ ARAUJO, José A., La crisis del Estado de Derecho Liberal. Schmitt en Weimar, Edit. Ariel, Barcelona, 1989. Asimismo ROTH, Joseph (1894-1939), El juicio de la historia: escritos 1920-1939, Pról., trad. y notas de E. Gil Bera, Eds. Siglo XXI, Madrid, 2004, en crónicas sobre el proceso por el asesinato de Walter Rathenau, en 1922, y en general sobre la cultura berlinesa de los años 20 . 
mar ${ }^{4}$, que fue también el del propio positivismo jurídico como emblema del Estado de Derecho formal (derecho como "forma" en función de la paz ${ }^{5}$ en la Teoría pura del Derecho de Kelsen), sobrevino agregado el presagiable desmoronamiento del modelo de representación política del Estado parlamentario, y tras su derribo, sucesivamente, la emergencia de otros nuevos fenómenos de legitimación en estructuras y formas de legalidad caracterizadas esta vez por el común empleo de una metodología y dialéctica decisionistas de índole autoritaria. Así, poco antes de producirse el estallido de la Segunda Guerra Mundial, las soluciones a problemas vinculados en la relación Derecho y Poder al conjunto de derechos y garantías sobre Libertad y Seguridad ofrecían ya con claridad el panorama de un profundo debilitamiento, provocado por la implantación de regímenes totalitarios -triunfo de la revolución bolchevique (Rusia) y ascenso y apogeo de las doctrinas fascistas (Italia y Alemania)- además de acelerado por el rápido incremento de las tensiones y rupturas diplomáticas en las que la Paz acabaría siendo finalmente destruida. Luego, ya durante el conflicto bélico, que tuvo al continente europeo como escenario y referencia principal de una conflagración de dimensiones planetarias, tanto la amenaza al programa ilustrado inspirador del reconocimiento y protección de derechos del hombre como la ignorancia o rechazo a los avances nacionales e interestatales -aún tímidos y asistemáticos- en materias de defensa de libertades civiles y políticas, no menos que el desentendimiento, transgresión y desprecio al conjunto de convenciones e instrumentos básicos de la comunidad internacional (Pacto de la Sociedad de Naciones. Ginebra, 1919) sobre el ius in bello y el derecho a la paz ${ }^{6}$, se hizo trágica e incontestable realidad en una atmósfera donde esa generalizada violación y absoluto abuso, alentada por una ideología -el nazismo- de extraordinaria degradación moral y brutalidad metódica, esencial y hasta metafísicamente deshumanizada, envolvió el propósito del aniquilar la condición bumana ${ }^{7}$.

5 Vid. KELSEN, Hans, "Die philosophischen Grundlagen der Naturrechtslehre und des Rechtspositivismus" (1928), en KLECATSKI, Hans- MARCIC, René- SCHAMBECK, Herbert (eds.), Die WienerRechtstheoretische, Europa Verlag, Wien-Frankfurt-Zürich, 1968, págs. 281-350, en espc. pág. 344.

${ }^{6}$ Para un examen doctrinal de de ius ad bellum e ius in bello, RUIZ MIGUEL, Alfonso, La Justicia de la Guerra $y$ de la Paz, CEC, Madrid, 1988. Vid también ARON, Raymond, Paz y guerra entre las naciones, trad. de L. Cuervo, Alianza Editorial S.A., Madrid, 1985. Sobre la profunda resistencia germana a aceptar la implantación internacional un codex belli como lex scripta es muy recomendable lo escrito por Ramiro de MAEZTU durante su estancia londinense y vinculación a los círculos del socialismo fabiano para Introducción (págs. 11-53, y en espc. págs. 31-39) a TOYNBEE, Arnold J., El terrorismo alemán en Bélgica. Narración basada en los documentos, Hayman, Christy \& Lilly, Ltd., Londres, 1917.

7 ARENDT, Hannah, Eichmann en Jerusalén (1963-1965), trad. de C. Ribalta, Edit. Lumen, Barcelona, 1999; JASPERS, Karl, El problema de la culpa, (1945-1946), trad. de R. Gutiérrez Cuartango e introd. de E. Garzón Valdés, Paidós-ICE de la Universidad Autónoma de Barcelona, Barcelona, 1998. Vid. también BILBENY, Norbert, El idiota moral. La banalidad del mal en el siglo XX, Anagrama, Barcelona, 1993. 


\section{Una nueva seguridad. Ayer, no hace aún el siglo}

La derrota militar del dominio nazi, para la que fue necesaria la alianza de las principales potencias internacionales, generó también durante los primeros años de posguerra un basto compromiso de diálogo multilateral y autocrítica del que será expresión el consenso moral adoptado en la Declaración Universal de Derechos del Hombre ${ }^{8}$, aprobada por la Asamblea General de Naciones Unidas el 10 de diciembre de 1948, plasmando allí el establecimiento de una pauta común para todas las naciones y el ideal de realización del ser humano libre. La etapa histórica que inauguraba se subsumía en una concienciación crítica de la incivilidad concluida desde la introspectiva de las atrocidades practicadas en Auschwitz (se cumplen ahora 60 años de la liberación de este campo de exterminio, el 27 de enero de 1945), así como del paulatino, aunque todavía muy limitado, conocimiento de la represión concentracionaria puesta en marcha por Stalin en Siberia. En el Considerando segundo del preámbulo de esa Declaración se lee que, en efecto, "el desconocimiento y menosprecio de los derechos del hombre han originado actos de barbarie ultrajantes para la conciencia de la humanidad".

No obstante, en absoluto se trataba de rescatar y reproducir el agotado paradigma de la vieja seguridad, básicamente organizado en procedimientos tendentes a evitar o suavizar las domésticas incertidumbres pequeño-burguesas caracterizadoras del modelo de nacionalismo de Estado liberal. Aquella clase de seguridad -tal vez la única concreta e históricamente determinada que el hombre moderno alcanzó a conocer- fue la primera víctima sacrificada en el extraordinario incendio que abrasó todo el mundo contemporáneo 9 . La inseguridad quedaba ya definitivamente instalada en el estándar de vida de una Humanidad que para entonces, pese a vivir una época de profunda desconfianza, o tal vez por lo que esa misma crisis significaba, se decidía sin embargo a proclamar su fe ("como la aspiración más elevada del hombre") en "el advenimiento de un mundo en el que los seres humanos, liberados del temor y de la miseria, disfruten de la libertad de palabra y de la libertad de conciencia". En adelante, los derechos humanos no actuarían para garantizar la seguridad, que para siempre dejó de existir, e incluso respecto de la cual se era en gran medida consciente que tampoco la sola recuperación de los restos de la herencia ilustrada (de tradición individualista) podría devolver a la existencia ${ }^{10}$, sino para preservar la Paz, que sólo a tan alto precio

\footnotetext{
${ }_{8}^{8}$ Reproducida en PECES-BARBA, Gregorio- HIERRO, Liborio- ÍNIIGUEZ DE ONZONO, Santiago- LLAMAS, Ángel (eds.), Derecho positivo de los Derechos humanos, Editorial Debate, Madrid, 1987, págs. 274-280. Sobre su genealogía textual y política, CASSESE, Antonio, Los derechos humanos en el mundo contemporáneo (1988), trad. de A. Pentimalli Melacrino y B. Ribera de Madariaga, Edit. Ariel, Barcelona, 1991 págs. 31 y ss.

9 Vid. AMERY, Carl, Auschwitz ¿Comienza el siglo XXI? Hitler como precursor, trad. de C. García Ohlrich, Turner/ FCE, Madrid, 2002,

${ }^{10}$ Así, la transacción comunitarista del art. 29.1: "Toda persona tiene deberes respecto a la comunidad, puesto que sólo en ella puede desarrollar libre y plenamente su personalidad"
} 
pudo ser recuperada. Nunca más, o mejor, nunca jamás, el “ideal de ser humano libre" podría realizarse sin permanecer liberados del temor (y de la miseria), repetirán también con insistencia el Pacto Internacional de Derechos Civiles y Políticos (New York, 16 de diciembre de 1966) [Reconociendo segundo] y el Pacto Internacional de Derechos Económicos, Sociales y Culturales (New York, 16 de diciembre de 1966) $[\text { Reconociendo segundo }]^{11}$. La libertad humana únicamente sería posible velando y protegiendo el en todo ex novo estatus jurídico de la emancipación del miedo (y del mandato legal de desarrollo económico) obtenido a través de la Democracia y la Paz desde sus condicionante históricos inmediatos, la suspensión de la Libertad en los fascismos y el horror de la reciente Guerra.

\section{La seguridad de hoy. Ahora, ya en este siglo}

Aquella concepción, formada en el juicio valorativo práctico sobre la relevancia y responsabilidad del miedo, y fuere que en su construcción teórica basilar (Reconociendo sobre innata dignidad del ser humano) se inclinara hacia la fundamentación ética neokantiana del derecho justo ${ }^{12}$, lo hiciera a favor de recobrar la antigua idea de derecho natural ${ }^{13} \mathrm{o}$, a diferencia de cualquiera de ambas, más bien se mostrara partidaria de reivindicar antes sobre todo su vertiente jurídica de positivación con base en el valor de la dignidad de la persona ${ }^{14}$, es lo cierto que abrió un nuevo rumbo en la historia de los Derechos humanos.

Esa idea de los Derechos humanos iba a producir, de hecho, una fundamental transformación en el curso de su historia. Estrenaba capítulo al establecer para ellos la perspectiva no de salvaguarda de la Seguridad, sino de convicción en la esperanza preservativa de la Paz; y precisamente porque la radical experiencia del miedo y su trágica catarsis no representaban un principio abstracto, planteado por fuera de las condiciones históricas, como un golpe del Destino, sino una amenaza que efectivamente ya materializó sobre la realidad por decisiones y responsabilidades imputables. El Holocausto, pues, había demostrado "tanto la necesidad prudencial de los derechos humanos como su intrínseca fragilidad"15.

\footnotetext{
${ }^{11}$ Reproducidos en Derecho positivo de los Derechos humanos, cit., págs. 361-378 y 379-388.

${ }^{12}$ Vid. RADBRUCH, Gustav, "Leyes que no son derecho y Derecho por encima de las leyes" (1946), en RADBRUCH, G.- SCHMIDT, E.- WENZEL, H. (eds.), Derecho injusto y Derecho nulo, Edit. Aguilar, Madrid, 1971, págs. 121.

${ }^{13}$ Vid. BERLIN, Isaiah, "La unidad europea y sus vicisitudes" (1959), en El fuste torcido de la Humanidad. Capitulos de historia de las ideas, (HARDY, H. - ed. (1990)), trad. de J.M. Álvarez Flores y Pról. de S. Giner, Eds. Península, Barcelona, 1992, en espc. págs. 190-194. Recogido también en BERLIN, Isaiah, Antología de ensayos, (ABELLÁN, J.- ed. e introd.) Edit. Espasa Calpe S.A., Madrid, 1995, págs. 415-451.

${ }^{14}$ Vid. PECES-BARBA, Gregorio, El fundamento de los derechos humanos, Edit. Debate, Madrid, 1989 y La dignidad de la persona desde la Filosofia del Derecho, Dykinson, Madrid, 2003.

${ }^{15}$ IGNATIEFF, Michael, Los derechos humanos como política e idolatría, introd. de A. GUTMANN, coment. de APPIAH, K. A. et al., trad. de F. Beltrán Adell, Eds. Paidós Ibérica S.A., Barcelona, 2003, pág. 100.
} 
Los Derechos humanos se edificaban ahora desde el testimonio de la inseguridad (del miedo como temor y espanto por lo ocurrido en el pasado, o como medrosía en un porvenir apocalíptico ${ }^{16}$ ), más que a partir de la seria convicción y hasta confiable expectativa de su eliminación inmediata.

Es así, me parece, como se instaura un compromiso, histórico antes que nada, y un equilibrio, de carácter lógico sobre todo, entre Libertad y Seguridad (frente al miedo) desde la Paz (frente a la guerra) como reducción auténtica y efectiva del riesgo. O lo que es igual, una posición estratégica de alerta (preservar la Paz) versus una medida táctica (garantizar la Seguridad), claramente diferenciables entre sí, pues mientras la primera conduce a mitigar los efectos del riesgo desde su aceptabilidad, la segunda sólo puede intensificarlo, así como también porque la primera es cuantificable (control y evitabilidad de consecuencias negativas del riesgo potencial, latente), y no lo es la segunda, que incapaz de minimizarlo se expone con la amenaza, aún siquiera conminatoria, a alentar y desatar en una escalada creciente y no dominable su activación, su virulencia ${ }^{17}$.

Pero hoy, en la actualidad, ni ese compromiso ni ese equilibrio se ha mantenido, incumplido el uno y el otro roto. Y la fragilidad de los derechos, que nuestro desideratum había convertido en triunfos, ha quedado en entredicho y a la vista, aunque tal evidencia responda a patrones distintos de aquellos que presidieron su origen de posguerra ¿Qué ha sucedido?

Los días 11-S. 2001 (New York, World Trade Center. Washington, Sede del Pentágono) y 11-M. 2004 (Madrid, Estación de Atocha) ofrecieron a nuestro mundo contemporáneo las imágenes del abismo. Las contemplamos en una visión tan sobresaltada y próxima, tan pavorosa, como imposible de sobrellevar. Era inútil tratar de sobreponerse a la inmediatez de aquel horror. Y en su desconcierto, las sociedades modernas (occidentales, democráticas y postindustriales) descubrieron de pronto, concretada en la retina de cada uno de nosotros, la colosal estatura de una amenaza imprevista para la que no se hallaban prestas: el ataque del terrorismo transnacional, global. En esos instantes gran parte de la presupuestaria fiabilidad fundada en la fragilidad preservativa de la "sociedad del riesgo", y en verdad vale aquí emplear tal expresión (Risiko-

\footnotetext{
${ }^{16}$ Aun sin las precisas matizaciones, que no es caso desarrollar aquí, con medrosía del porvenir apocalíptico aludo al intensísimo y disuasorio miedo sentido durante los años de la "guerra fría" ante la total destrucción del género humano, en un holocausto mundial, resultado del empleo de armas nucleares.

${ }^{17}$ En el tercero de los artículos preliminares para la paz perpetua entre los Estados, ya señalaba Kant que los ejércitos permanentes (miles perpetuus) suponían "una amenaza de guerra para otros Estados con su disposición a aparecer siempre preparados para ella. Estos Estados se estimulan mutuamente a superarse dentro de un conjunto que aumenta sin cesar y, al resultar finalmente más opresiva la paz que una guerra corta, se convierten ellos mismos en causa de guerras ofensivas". Vid. KANT, Inmanuel, La paz perpetua (1795) trad. de J. Abellán, Present. de A. Truyol y Serra, Edit. Tecnos, Madrid, 1985, pág. 7.
} 
gesellschaft $)^{18}$, sufrió un interno y sustantivo removimiento. Entre los efectos de esa honda conmoción a poco se advertiría uno capaz de afectar a elementos doctrinales, todavía vigentes en aquel momento, sobre la comprensión de los Derechos humanos en sus planteamientos sobre Paz, Libertad y Seguridad. El epicentro del seísmo se localizaba en la mutación que la vívida y muy sensible experiencia de los acontecimientos produjo sobre la noción de "riesgo". La extremada cercanía con que los sucesos del 11-S (como después asimismo en el 11-M) fue mediáticamente ofrecida, llegó hasta su límite más extra-simbólico, como una ventana "en directo" a lo que no parecía suceder donde tenía lugar ${ }^{19}$, determinando que el modo de percepción y entendimiento del "riesgo" cambiase a extraordinaria velocidad.

La situación de "riesgo" (temor a la eventual repetición de "actos de barbarie ultrajantes para la conciencia de la humanidad") trastocó de contingente en inminente, esto es, en "peligro"20. La posición estratégica de alerta (preservar la Paz), había funcionado mal, había fallado, y así se daba a ver per se ante los ojos del mundo entero. Ya con todas las alarmas disparadas, ya verdaderamente en "estado de alarma", en pánico, la única medida táctica, al comienzo sobre todo prioritaria y desde luego del todo priorizada, estribó en "garantizar la seguridad". La "sociedad del riesgo" pasó a ser, operativamente, "sociedad del peligro" (Gefahrgesellschaft), lo que en su urgencia y a la postre hacía admisible optar como respuesta por maximalizar el uso de la fuerza en defensa, por suspender e interrumpir la Paz, por la intervención "preventiva", por la Guerra en definitiva.

En ello, la consecuencia para la significancia jurídica de los Derechos humanos ha sido que de la fragilidad por riesgo se ha venido a parar en su vulne-

\footnotetext{
${ }^{18}$ Vid. para un examen de la idea de "sociedad del riesgo" diversos trabajos de BECK, Ulrich, como Risikogesellschaft. Auf dem Weg in eine andere Moderne, Suhrkamp, Frankfurt, 1986 y en espc. Gegengifte. Die organisierte Unverantwortlichkeit, Suhrkamp, Frankfurt, 1988 y Die Erfindung des Politischen. Zu einer Theorie reflexiver Modernisierung, Suhrkamp, Frankfurt, 1993, y de GIDDENS, Anthony, Consecuencias de la modernidad, trad. de A. Lizón Ramón, Alianza Editorial S.A., Madrid, 1993 y Modernidad e identidad del yo. El yo y la sociedad en la época contemporánea, trad. de J. L. Gil Aristu, Eds. Península, Barcelona, 1995. Asimismo LUHMANN, Niklas, desde su enfoque sistémico, Soziologie des Risikos, De Gruyter, Berlin, 1991. Sobre las respectivas posiciones puede consultarse BERIAIN RAZQUIN, Josetxo (ed.), Las consecuencias perversas de la modernidad: modernidad, contingencia y riesgo, trad. de C. Sánchez Capdequi, Anthropos, Barcelona, 1996. Sobre la penetración e influencia del concepto "sociedad del riesgo" en la doctrina penal, PÉREZ DEL VALLE, Carlos, "Sociedad de riesgos y reforma penal", en: Poder Judicial, 43-44, 1996 (II), págs. 61-84.

${ }^{19}$ MUÑOZ MOLINA, Antonio, Ventanas de Manhattan, Edit. Seix Barral S. A., Barcelona, 2004, págs. 76-80.

${ }^{20}$ Modestamente, creo que ni formulación terminológica aventaja y mejora otras habitualmente empleadas. $V$. gr., HASSNER, Pierre, "La signification du 11 septembre. Divagations politico-philosophiques sur l'événemet", en: Esprit, 11, 2002, págs. 153-169, cuando al sostener que la política moderna tiene como proyecto sustituir por pasiones serenas y frías las pasiones violentas y los intereses apasionados, señala que si el siglo XX puso de manifiesto los límites de esta empresa, el XXI nace con un nuevo déficit, el del terrorismo inspirado por el fanatismo religioso y el contraterrorismo maniqueo inspirado por el "miedo". A mi modo de ver, la única conclusión relevante de este uso de la expresión sería en realidad metalingüística, mostrando al miedo, sobre todo, como una infraideología.
} 
rabilidad por peligro. En otras palabras, la Seguridad se ha convertido en el agujero negro de los derechos, del Derecho incluso ${ }^{21}$ (también como certeza y previsibilidad). Y es así, en esos términos, que "garantizar la Seguridad" comporte igualmente un signo inconfundible de contramodernidad para con el respeto de los Derechos humanos y de retracción del desarrollo de nuestra historia y cultura jurídicas.

\section{Los Derechos humanos como “daños colaterales” de la seguridad}

Es a menudo complicado no seducirnos por la fantasía de imaginarnos en una situación que semejaría la de la noche en que habiéndonos acostado al sueño de la razón, amaneciéramos la mañana siguiente en la vigilia de la voluntad. Que confiando compartir lecho con los postulados racionales y universalmente válidos de Kant, nos descubriésemos entre Hobbes y Marx; de un lado "el estado de naturaleza", al otro "la clase".

Ciertamente, como escribe Muñoz Molina 22, "las libertades se dan fácilmente por supuestas, pero no hay nada más frágil que la democracia, entre otras cosas porque no tiene nada de natural. Lo natural es el abuso de los fuertes sobre los débiles, la adhesión a lo más cercano y la hostilidad a lo extranjero o lo desconocido, el perjuicio y no la curiosidad, el impulso y no la razón. Es necesario recordar continuamente lo que ha costado ganar lo que tenemos, y lo reducido que es en el mundo el espacio de las democracias y del imperio de la ley, para darnos cuenta del valor que tiene y de lo fácil que sería perderlo". Pues bien, en esta percepción se contienen dos apreciaciones tan perfectamente suscribibles como diferenciables, que no obstante exacerbadas e in distinguidas entre sí, conducen a error.

La experiencia desde mediados del siglo XX subraya en realidad la insuficiencia y el rechazo de Hobbes como de Marx, aunque asimismo también cuestiona seriamente una inmoderada actitud triunfalista respecto de determinados presupuestos, nunca o al menos no lo bastante demostrados. Esa etapa de la centuria anterior a ésta en que vivimos demuestra con dificultad -y más bien prueba lo contrario- el axioma de que bien vale la pena perder libertad y democracia para ganar seguridad. Es frecuente, en efecto, que resultemos atraídos por esa sugestión intelectual. Pero la impresión que ella nos brindara sería al final falsa, pues en definitiva el devenir

${ }^{21}$ Vid. CARMONA RUANO, Miguel, "El impacto jurídico del 11 de septiembre", en: Jueces para la democracia, 45, noviembre/2002, págs. 81-91: "los atentados no sólo produjeron la demolición brutal de edificios simbólicos, sino que las Torres Gemelas pueden estar arrastrando en su caída principios centrales de nuestra cultura jurídica" (pág. 81). Asimismo ROBINSON, Mary, "Los derechos humanos, ensombrecidos por el 11-S”, en diario El País (Madrid), 4/07/2002.

${ }^{22}$ MUÑOZ MOLINA, Antonio, "Ciudadanía, Culturas, Libertades", en VV.AA., Extranjeros y Derecho penal, Cuadernos de Derecho Judicial IV, 2003, CGPJ, Madrid, 2004, págs. 75-76. 
de la historia del mundo contemporáneo entre los siglos XIX y XX y de éste al XXI, no vino a modificar ni el curso de la precedente, ni tampoco otro más antiguo $^{23}$. Quienes trataran de convencer o persuadir acerca de que no fue así estarían falseando la Historia, engañando. De siempre y a lo largo de la Historia, la libertad y la democracia suscitaron recelo y desconfianza. Con todo, nada en lo anterior impide reconocer que quizás hayamos olvidado demasiado pronto y fácilmente los importantes sacrificios, es decir, desatendido al valor de las renuncias, que el arribar a la modernidad nos ha llevado y exigido.

En tal sentido, lo que sí parece haber sucedido casi como de un día para otro y como casi de la noche a la mañana es un cambio del tipo de fragilidad que advertía e informaba sobre el valor de los Derechos humanos. Éstos, por valiosos, eran frágiles, y también en esa fragilidad residía su valor. La fragilidad de los derechos que en el mundo contemporáneo de la era posterior a la II Guerra Mundial tomaba su circunstancia precisamente de anunciar con bastante fiabilidad el temible riesgo a que su deterioro y erosión conducía, ha visto trastornada su naturaleza con la alteración de su original imagen de salvaguarda frente al fascismo y de freno contra la guerra mediante una variación donde el ideal de libertad se proclama en el antiterrorismo, y la preservación de la Paz en la garantía de Seguridad.

Esa mudanza implica sin duda una aguda transfiguración, una metamorfosis en sentido etimológico, o sea, un más allá de la figura o aspecto, por tanto donde cualquier parecido con el estado inicial se ha desvanecido. Y frágil se predica desde ahora de lo enteco, caduco, perecedero, como endebles o sin pujanza, transitorios o pasajeros, precarios o inestables comenzarían a ser también desde ahora, sin tiempo de descuento, los derechos. Los Derechos humanos habrían perdido su condición de infungibles en el espacio y en el tiempo. En la nueva situación ocuparían una posición destinada a padecer y soportar "daños colaterales".

Desde luego, es claro que la conciencia de los derechos en su papel transfronterizo frente a la ghettoización de la universalidad ${ }^{24}$ ha registrado una mayor y más evidente tendencia al adelgazamiento y la clausura, en especial entre los pueblos y gobiernos del mundo acostumbrados a vivir sin pensar en el terrorismo, o sentir el temor a su violencia de un modo en todo distinto del actual ${ }^{25}$. Normalmen-

${ }^{23}$ ROUSSEAU, Jean Jacques, Contrato Social (1762), trad. de M. Armiño, Alianza Editorial S.A., Madrid, 1991 (8 reimp.), cap. I, pág. 10: "El hombre ha nacido libre y por doquier está encadenado".

${ }^{24}$ DE LUCAS, Javier, Derechos humanos y xenofobia frente a una sociedad plural, Eds. Temas de Hoy S.A., Madrid, 1994, y CALVO GONZÁLEZ, José, "Ghettoización de la Universalidad y futuro de los Derechos Humanos", en: Derechos y Libertades, 5/1995, págs. 405-412. Vid. también DE LUCAS, Javier, Europa: ¿Convivir con la diferencia? Racismo, Nacionalismo y Derechos de las minorías (1992), Edit. Tecnos, Madrid, 1994 y Puertas que se cierran. Europa como fortaleza, Icaría, Barcelona, 1996.

${ }^{25}$ Vid. RAMONET MÍGUEZ, Ignacio, Guerras Del siglo XXI. Nuevos miedos, nuevas amenazas, Edit. Mondadori, Barcelona, 2003. 
te esas poblaciones eran también las mismas que reaccionaban con la fobia hacia lo extranjero o diferente, y se hacían representar por sistemas e instituciones que exhibían una continua exaltación del nacionalismo de Estado. Por esa razón ha sido en ellas, que así ya apuntaban una metamorfosis del miedo ${ }^{26}$, donde mayormente la idea de peligro está arraigando o ya lo ha hecho. Allí es también donde más se acentúa la restricción de las libertades y el retroceso en la igualdad.

Además, de manera particular y palpable, el aprecio por la legitimidad de los derechos -por la del Derecho- todavía se compromete más de fractura y acaba dañado cuando, una vez reformulados en garantía de la Seguridad, sirven instrumentalmente a la oportunidad vindicativa. La venganza es la fuerza que revoca la distancia entre la justicia y la injusticia. Llegando a ese punto, el creciente deseo y clamor de venganza impide discutir con serenidad y ser oído al proponer posibles explicaciones sobre los móviles y coordenadas del terrorismo, sea que se concreten en el fracaso del capitalismo de mercado (o fundamentalismo de mercado) ${ }^{27}$ para tratar a los pueblos del Tercer Mundo con justicia (liberarlos de la miseria) e incluirlos en el futuro global, o se tracen como brutal respuesta al materialismo laico y la agresiva macdonalización de las sociedades tradicionales $^{28}$.

Sin embargo, hoy, pasados cinco años desde el final del segundo milenio, deberíamos discernir con mayor claridad el sentido y valor del fin del viejo mundo de la seguridad, y comprender mejor el del mundo que hasta ayer conocimos. El contundente paso de uno a otro milenio ha producido el pliegue de una regresión política y jurídica que demanda, por encima incluso de las valientes condenas morales que no desvían la mirada de los actos injustos, remediar el cuarteamiento y grietas abiertas durante el siglo XX en el Estado constitucional de Derecho $^{29}$, y detener su proceso de empeoramiento y degradación.

Por tanto, únicamente la decisión de acometer en serio una tarea de compostura y consolidación hará aún posible continuar construyendo en firme sobre los logros en derechos de la era posterior a la II Guerra Mundial, evitando exponer la fragilidad que presidió su epifanía contemporánea, y que en el escenario histórico del presente se reclama como su principal robustez, a una banalización de su significancia.

\footnotetext{
${ }^{26}$ Vid. ESCOBAR, Roberto, Ironia e paura del quotidiano, Edizioni Unicopli, Milano, 1989 y Metamorfosi de la paura, Il Mulino, Bologna, 1997.

${ }^{27}$ Vid. STIGLITZ, Joseph E., Malestar de la globalización, trad. de C. Rodríguez Braun, Eds. Taurus, Madrid, 2002.

${ }^{28}$ Vid. CHOMSKY, Noam, 11/09/2001, trad. de C. Aguilar, RBA Libros S.A., Barcelona, 2001.

${ }^{29}$ MARTÍNEZ DE PISÓN, José, Tolerancia y derechos fundamentales en las sociedades multiculturales, Edit. Tecnos, Madrid, 2001, pág. 206.
} 
Tal resolución, si es sincera, exige necesariamente comenzar reparando el más grave resquebrajamiento; el de la regla procesal garantista que, asumida en la práctica totalidad de los ordenamientos jurídicos internos, fisura sin embargo en el marco de la legalidad interestatal: toda persona tiene derecho a "un tribunal independiente e imparcial (...) para el examen de cualquier acusación contra ella en materia penal" (DUDH art. 10) ${ }^{30}$. En la nueva sociedad del peligro terrorista se lo vulnera al permitir que los ofendidos por una conducta antijurídica, las víctimas de los atentados, "adopten simultáneamente el papel de acusador, juezy y ejecutor"31. El intento por afianzar la universalidad de esa garantía, que en efecto se ha mostrado muy complejo y problemático en la vía diplomática mientras el modelo que articula la relación y conducta entre las naciones todavía opera con una fórmula comprimida y privilegiada de la preservación de la Paz mundial -el derecho de veto a disposición de los Estados miembros permanentes del Consejo de Seguridad de Naciones Unidas- sólo podrá prosperar a través de una instancia jurídica supranacional, la Corte Penal Internacional ${ }^{32}$, que a razón de la universabilidad de su jurisdicción, actuando como juez natural, persiga y castigue eficazmente la barbarie de los crímenes contra la Humanidad, pero igualmente patrocine y proteja la paz internacional frente a la inseguridad introducida por un ejercicio desconcentrado de la seguridad o la privatización de la agenda de seguridad global por algún grupo de países. Desde luego, como he indicado, de nada sirve tratar de ocultar que el vislumbre de ese horizonte aparece a una distancia aún demasiado lejana del punto a partir del cual hoy se mueve la política internacional de las naciones más poderosas del planeta, y que para imprimir una variación en el curso de esa dirección sería preciso comprometer, de hecho, pero sobre todo de Derecho, justo la participación de los mismos gobiernos que con más fervor lideran la resistencia a que ese diferente sesgo tenga ocasión a producirse. Esta apreciación de la realidad, sin embargo, no debe hacernos reducir cualquiera imaginables conclusiones a la constatación de lo que nos encontramos ante lo que vulgarmente se conoce como un problema de tipo "callejón sin salida", sin solución posible, sino servir de señal de hacia dónde no debemos continuar la marcha. Es por eso lo más inquietante comprobar que

\footnotetext{
${ }^{30}$ Asimismo art. 14.1 del Pacto Internacional de Derechos Civiles y Politicos.

${ }^{31}$ BECK, Ulrico, Sobre el terrorismo y la guerra (2002), trad. de R. S. Carbó, Eds.Paidós Ibérica S. A., Barcelona, 2003, pág. 35. Vid también HELD, David, “Globalización: el peligro y la respuesta”, en diaro El País (Madrid), 4/07/2002: "El atentado terrorista del 11-S contra las Torres Gemelas y el Pentágono fue un momento definitivo para la historia de las generaciones actuales. En respuesta, EEUU y sus aliados más importantes podrían haber decidido que la forma más importante y eficaz de detener el torrente de terrorismo global sería reforzar la legislación internacional y ampliar las funciones de las instituciones multilaterales. Podrían haber decidido que era importante que ningún poder o grupo pudiera actuar por sí solo como juez, jurado y verdugo".

${ }^{32}$ CARRILLO SALCEDO, Juan Antonio (Coord.), La criminalización de la barbarie: la Corte Internacional Penal, CGPJ, Madrid, 2000; LIROLA DELGADO, Isabel- MARTÍN MARTÍNEZ, Magdalena M., La Corte Penal Internacional. Justicia versus Impunidad, Edit. Ariel, Barcelona, 2001 y GALGO PECO, Ángel (Dir.), Derecho penal supranacional y cooperación jurídica internacional, (Cuadernos de Derecho Judicial XIII-2003), CGPJ, Madrid, 2004.
} 
desde una óptica de alcance más regional tampoco el panorama lleva allí camino de mejorar, y que el espeso nublado que se interpone a la visión en profundidad sigue extendiendo su oscuridad antes que disiparse. $V \cdot g r:$ especificaciones del texto de la Constitución Europea que para adelantarse a la amenaza terrorista consienten emprender acciones preventivas ${ }^{33}$.

Al propio tiempo, ya en niveles de actuación circunscritos a lo nacional, debería procederse también a subsanar y restablecer, es decir, a restaurar y reponer, el sello de origen y marca más contrastada de la fragilidad de los derechos y garantías en cuanto "ley del más débil" 34 . Será entonces imprescindible, lo es ya a virtud del cariz que presentan, rehacer las políticas regionales de seguridad y de seguridad doméstica en no pocos Estados donde se auspicia y practica una ideología jurídico-política de la seguridad consistente en resguardar a sus nacionales de lo presentido (asimismo como sentimiento anticipado) y expuesto como el peligro, por cuanto enemigo, del extraño a la comunidad. La idea de ese enemigo (enemicus) recoge del derecho romano arcaico, aún en época más primitiva que la de las XII Tablas, lo presentando en su determinación objetiva como la del que, perteneciendo a una misma familia, de la que desertaba o a la que traiciona, había dado muerte al padre, a la madre o a algunos de los parientes dentro del cuarto grado, y así también el modo organizar la función persecutoria y represora instrumentada por entonces a través de la continuación del rastro trastiberum (más allá del río Tíber como frontera del espacio de identidad comunitario de las familias) y el instituto de la vis privata (resarcimiento vengativo). El Derecho en nuestros días aprovecha de ese conjunto de rasgos, si bien redibujándolos; ahora reviste con la categoría de enemigo al ajeno, extraño o extranjero; ahora anticipa la tutela a su acción antijurídica, que además se alegoriza socio-cultural y políticamente en el peligro de dar muerte a la patria (Estado nacional), matria (organización regional) o alianza de sangre (allegados consanguíneos, de parentesco más próximo, semejantes a nosotros porque les alcanza el "aire de familia"); ahora amuralla (res sancte) el recinto de la identidad común (pomerium) controlando el acceso exterior desde puertas (fores, la puerta vista desde el que está dentro de la casa, domi; v. gr: foris o foranus versus domesticis, domesticum) por las que filtra su entrada (cierra el paso y deja fuera) con base en marcadores antropológicos [raza (blanca), religión (cristiana), civiliza-

\footnotetext{
${ }^{33}$ Tratado por el que se establece una Constitución para Europa, parte primera, título V, capítulo III, art. I-43 a) establece en matera de regulación particular relativa al espacio común de libertad, seguridad y justicia, como cláusula de solidaridad, la movilización por la Unión de "los instrumentos de que disponga, incluidos los medios militares puestos a su disposición por los Estados, para prevenir la amenaza terrorista en el territorio de los Estados miembros". Con la dicción empleada no se aparta del programa operativo a una intervención militar preventiva.

${ }^{34}$ FERRAJOLI, Luigi, Derechos y garantías. La ley del más débil, (1994 y 1994), trad. de P. Andrés Ibáñez y A. Greppi, con Pról. de P. Andrés Ibáñez, Edit. Trotta, Madrid, 1999.
} 
ción (occidental)] o a partir de la procedencia geográfica [continente (europeo, Primer Mundo)], a fin de contingentar (porque sin duda se piensa en clave de mercancías y servicios) la producción y desarrollo económico-industrial interior; ahora, finalmente, ya monopolizado el uso de la fuerza por los poderes y órganos del Estado, es el propio sistema jurídico quien declara y ejecuta la respuesta de aversión, hostilidad y enemiga.

El Derecho es de esta manera real y verdadero responsable de producir una rarefacción de la atmósfera de garantías procesales y alimentar un estado de expansión punitiva habiendo elaborado para ello una construcción dogmática que va más allá del "derecho penal de la puesta en riesgo", formulada ya como "derecho penal del enemigo" 35 , y asimismo, agente directo y eficaz, so pretexto de regulación del fenómeno inmigratorio ${ }^{36}$, en disponer mecanismos para la demonizadora segregación espacial y social de determinados colectivos.

En una situación de menoscabo como ésta pienso que no basta ya tan siquiera con reconstruir el Estado constitucional de Derecho. Es fácil constatar que el cuarteamiento es en este siglo XXI una hendidura demasiado profunda, que hoy las grietas están haciéndose auténticas quebraduras. Es por eso que la precisa y necesaria acción frente a la progresiva agravación de esos detrimentos tiene que decidirse a ir más allá, no limitándose pues, sólo, a sanear aquello que al modelo de la democracia constitucional y la idea de constitucionalismo les impide recuperar su primitiva fisonomía, sino procurar una rehabilitación que los revalorice. Y por eso también creo que, mientras no sea definitivamente tarde, esto es, mejor antes que después, habríamos de asumir que tal labor conlleva reemplazar, entendido como resituar, algunos de nuestros criterios acerca de ellos, y al menos dos.

Uno sería, a mi entender, siempre buscando que "los derechos" resistan en la función de fundamentalidad, de autoridad ${ }^{37}$, que en el sistema jurídico les cumple de desarrollar, ir a la readquisición del lugar que a la soberanía popular incumbe

\footnotetext{
${ }^{35}$ Vid. PORTILLA CONTRERAS, Guillermo, "EL derecho penal del enemigo", en: Mientras tanto, 83, 2002, págs. 78 y ss., y JAKOBS, Günther- CANCIO MELIÁ, Manuel, Derecho penal del enemigo, Civitas Eds. S.L., Madrid, 2003. Esta dogmática que sostiene la política criminal y modelo de intervención penal concuerda asimismo en el giro experimentado, de los años 80-90 al presente, en el pensamiento criminológico, donde se pasa de una posición dominante donde el delito aparece como producto de los órganos de control social a la actual en que se lo muestra fruto de la voluntad delincuente.

${ }^{36}$ DE LUCAS, Javier, "Inmigrantes, extraños a la comunidad, enemigos de ida y vuelta en la respuesta del Derecho a la inmigración", en: Sociologia del Diritto, 2, 2004, págs. 23-34. Vid. también SOLÉ, Carlota- PARELLA, SoniaALARCÓN, Amando- BERGALLI, Valeria y GIBERT, Francesc, "El impacto de la inmigración en la sociedad receptora. El caso del sur de Europa", en: Revista Española de Investigaciones Sociológicas, 90, abril-junio 2000, págs. 131-158

${ }^{37}$ PALOMBELLA, Gianluigi, L'autorità dei diritti. I diritti fondamentali tra istituzioni e norme, Editori Laterza, Roma-Bari, 2002.
} 
como criterio de sentido reconstituyente para la democracia constitucional ${ }^{38}$. El otro, ir en busca de algún nuevo criterio en el que solventar cómo remover los límites de pertenencia de la ciudadanía a la nacionalidad, cómo trasladar dentro, es decir, de qué modo incluir a quienes hoy permanecen a las puertas de "los derechos" y excluidos de sus garantías, porque al no alcanzarles la condición de nacionales tampoco disponen de los privilegios que a éstos les corresponden en el reconocimiento de la universalidad, aun cuando como tal ésta fuera proclamada por encima cualquier cierre político-espacial ${ }^{39}$. La solución, quizás, consista en ensanchar el ámbito, globalizar, "cosmopolitizar" el espacio constitucional hasta identificarlo con una ciudadanía universal. De lo que sin embargo no cabe duda es que hasta ahora mero el trasvase inverso, de las convenciones internacionales carentes de garantías a los ordenamientos constitucionales, no ha dado el resultado apetecible, o no desde luego tan igual para todos y suficientemente universalizado como hubiera sido de desear, como fue lo deseado. Ello, en uno u otro caso, debería ponernos de manifiesto la conveniencia de refundar el constitucionalismo sobre bases diferentes a las actuales.

\section{Fragilidad de los derechos, en adelante}

Estamos en un tiempo en el que debemos asumir las realidades con sinceridad. En el tenso pulso a que esta época nos desafía los derechos humanos aparecen como las piezas más frágiles del sistema jurídico moderno, y todo él se halla ahora bajo la presión de un embate durísimo, no sólo de un amago relativamente intimidatorio. El pasado más reciente los presentaba en términos de protección y amparo, como el refugio más primario en que guarecerse y asegurarse ante la inseguridad, para liberarnos del temor (y la miseria), desde el horror de un testimonio histórico que explicaba con crudeza las infrahumanas consecuencias acarreadas de su negligencia y omisión, y para evitar que jamás volvieran de nuevo a repetirse. Pero el riesgo nunca estuvo completamente eliminado ni quedó tampoco suprimido, por lo que la base de su evitación era fundamentalmente cau-

${ }^{38}$ Vid. PALOMBELLA, Gianluigi, Constitución y Soberanía. El sentido de la democracia constitucional (1997), trad. e introd. ("De la nostalgia civil: la soberanía popular", pág. XIII-XXIV) de J. Calvo González, Edit. Comares, Granada, 2000: "Si queremos mantener activa la fuerza de nuestras democracias constitucionales debemos reconocer el punto en que las constituciones se ligan a las democracias y en el que ante ellas se detienen, en el que la soberanía popular se liga a las constituciones y en el que ante ellas se detiene" (pág. 140).

${ }^{39}$ FERRAJOLI, Luigi, Derechos y garantías. La ley del más débil, cit.: "Tomar en serio los derechos significa hoy tener el valor de desvincularlos de la ciudadanía como "pertenencia" (a una comunidad estatal determinada) y de su carácter estatal (...) Ello significa admitir de forma realista que no existe, a largo plazo, más alternativa a las guerras y el terrorismo que la efectiva universalización de aquéllos, siendo cada vez más actual e ineludible el nexo entre derechos fundamentales y paz afirmado en el preámbulo de la Declaración universal de 1948, y que, por tanto, la presión de los excluidos sobre nuestro mundo privilegiado alcanzará formas de violencia incontrolada, a menos que nos obliguemos a remover sus causas, quitando a la ciudadanía su carácter de status privilegiado y garantizando a todos los mismos derechos, incluidas las libertades de residencia y de circulación” (págs. 117-118). 
telar, precautoria. De ahí su fragilidad. Actuaban como balizas, y no tanto como baluartes, de la civilización contra la barbarie. Marcaban las zonas de peligro en que no debíamos introducirnos. Eran la señal de un non plus ultra; en adelante se abría un abismo devorador. Su reconocimiento era en realidad la celebración -esperanza en la memoria del horror ${ }^{40}$ - de un goal, más no aún del triunfo.

En la nueva época que está frente a nosotros, como en cualquier otra precedente, las oportunidades son tantas todavía como tantas puedan ser también las ocasiones que se pierdan. A lo largo de las últimas décadas del siglo XX hay que contar como ocasión perdida algunos de los errores que entonces se cometieron. Pero también, como oportunidad bien aprovechada, el acierto que representó de la progresiva implantación de libertades individuales hasta lograr una Democracia plena en la gobernación de muchos países. No es buena solución olvidar los problemas pendientes de respuesta y es uno de los más grandes errores infravalorar cualquiera solución que el pasado nos ofrezca, como pueda serlo la que sobre la cultura política de Occidente ha ejercido el perfeccionamiento de los marcos jurídico-institucionales en materia de derechos. $\mathrm{Al}$ medir la experiencia de éxitos y fracasos, al igual que al calcular cuál pueda ser la expectativa de unos o de otros, el presente de la fragilidad devaluada de los derechos procede sobre todo de la forma en que estructuramos las respuestas, las soluciones.

Al contrario de cuanto sucedía en el ayer de la seguridad, donde el mundo de la libertad más segura era aquel que más valoraba la seguridad, en el de hoy el mundo de la libertad más segura será aquel que más valore la inseguridad.

Dependiendo de la estructura en las que formemos las respuestas así serán las que obtengamos. Nunca la respuesta de la Paz puede consistir la "pacificación" de quien la amenaza.

\section{La seguridad de la Paz. De fabula docit}

La Humanidad pagó a altísimo precio, por dos veces en un mismo siglo, el coste de la desventurada negligencia y omisión de los derechos.

En la cultura de los Derechos durante la última mitad del siglo XX aún estaba vivo todo aquel sufrimiento. Los derechos simbolizaban una narrativa de trabajo; la del mítico sufrimiento de Sísifo. La enorme piedra, la que tantas veces escapó de nuestras manos rodando ladera abajo hasta el fondo del valle, había sido subida y encumbrada, tras un esfuerzo extremo, a lo más alto de la monta-

\footnotetext{
${ }^{40}$ Vid. MATE, Reyes, Memoria de Auschwitz. Actualidad moral y politica, Edit. Trotta, Madrid, 2003.

${ }^{41}$ ENZENSBERGER, Hans Magnus, Perspectivas de guerra civil, trad. de M. Faber-Kaiser, Edit. Anagrama, Barcelona, 1994, pág. 84
} 
ña. "Esa piedra era la Paz", ha escrito Enzensberger"1. Alzada hasta la cima, un lugar tan expuesto, tan comprometido, tan arriesgado, era necesario preservarla. No pudimos arreglar otro socorro que un enmallado de cuerdas. La malla de los derechos. Pero esa atadura de cuerdas, como las que Ocnos trenzara, también la devora hoy un asno: el asno de la ignorancia, de la estulticia, de la intolerancia, de la venganza. Sin la sujeción que le prestaba aquella trama de delgados hilos de los derechos, la piedra que ahora se tambalea no ofrece suficiente estabilidad. Puede estar cerca de caer, terminar aplastándonos y hecha mil pedazos.

El peligro de una Paz sin derechos es "la paz de la seguridad". 
